\title{
"Operación Mercedes":
}

\section{Monumento a la ciudadanía solidaria}

Jordi Hernich

Arquitecto

Email: henrich@coac.net
Antoni Remesar

CR Polis. Universitat de Barcelona

Email: aremesar@ub.edu

\section{Resumen}

La pandemia COVID19 que está causando estragos en la salud pública mundial, ha significado, también, la adecuación - temporal hasta el momento - de los procedimientos de trabajo en la enseñanza universitaria, tanto en lo que afecta a la impartición de clases como a lo referente a las actividades a desarrollar por los estudiantes .

La programación de la asignatura de Taller de Proyectos del Máster en Diseño Urbano de la Universidad de Barcelona, preveía centrar las actividades proyectuales del taller en la que 'podemos llamar "Operación Mercedes", un proyecto privado de regeneración urbana en el barrio barcelonés del Bon Pastor, consistente en convertir $90.000 \mathrm{~m} 2$ del antiguo solar fabril de la Mercedes-Benz, en un complejo residencial y de oficinas.

Según el Plan General Metropolitano (1976) vigente en Barcelona, este solar está calificado como 22a, es decir "Zona Industrial" y desde 2007, cuando Mercedes-Benz deja de operar en esta fábrica, configura una de las pocas áreas de reindustrialización de Barcelona. Su venta al grupo inversor Conren-Tramway, a finales de 2018, vuelve a resucitar los miedos vecinales sobre el uso de estas $9 \mathrm{Ha}$.

En el marco del proyecto de investigación HAR2017-88672-R. y de los acuerdos de colaboración con la asociación de vecinos, desde hace unos años introducimos temáticas de espacio público del territorio de Bon Pastor, en la asignatura "Taller de Proyectos" del Màster en Diseño Urbano. Dos objetivos. El primero explorar ideas de solución de problemas 
de espacio público con los estudiantes -mayoritariamente extranjeros-, funcionando el Taller a modo de "Laboratorio de Ideas" al tiempo que los trabajos sirven de prácticas n o curriculares. Segundo objetivo: aportar ideas proyectuales a los vecinos del Bon Pastor para la gestión y negociación de las diversas acciones a desarrollar en el barrio.

Por ello se planificó el trabajo de Taller del curso 2019-2020 para explorar las posibilidades de espacio público en esta nueva operación de Regenración Urbana. Los trabajos del taller se desarrollan en equipos multidisciplinares respondiendo a la formación previa de los estudiantes.

Cuando en marzo se decreta el confinamiento en España, vemos casi imposible el desarrollo del trabajo prevista en un modalidad on-line. Es por ello que se decide variar el tema, centrándolo en un Monumento a la Ciudadanía Solidaria -lo que permite una aproximación más individualizada al trabajo- , pero manteniendo la referencia territorial del solar de la Mercedes-Benz.

Palabras clave: Barcelona; Bon Pastor; Ciudadanía; Solidaridad; Monumento; Operación Mercedes

\section{Abstract}

The COVID19 pandemic, which is wreaking havoc on global public health, has also meant the adequacy- temporary so far - of the work procedures in university education, both in what affects the teaching and in relation to to the activities to be developed by the students.

The program of the Project Workshop subject of the Master in Urban Design at the University of Barcelona, planned to focus the project activities on what we can call "Operation Mercedes", a private urban regeneration project in the Barcelona's neighborhood of Bon Pastor, consisting of converting 90,000 m2 of the former Mercedes-Benz factory site into a residential and office complex.

According to the General Metropolitan Plan (1976) in force in Barcelona, this site is classified as 22a, that is, "Industrial Zone" and since 2007, when Mercedes-Benz stops operating in this factory, it has been one of the few reindustrialization areas in Barcelona. Its sale to the investment group Conren-Tramway, at the end of 2018, once again resuscitates neighborhood fears about the use of these $9 \mathrm{Ha}$.

Within the framework of the research project HAR2017-88672-R. and the collaboration agreements with the Bon Pastor's neighborhood association, for a few years we have been introducing themes of public space in the territory, in the subject "Project Workshop" of the Master in Urban Design. Two goals. The first one to explore ideas for solving problems regarding public space with students -mainly foreigners-, operating the Workshop as a "Laboratory of Ideas" while this activities serve as non-curricular practices. Second objective: to contribute project ideas to the residents of Bon Pastor for the management and negotiation of the various actions to be carried out in the neighborhood.

For this reason, the Workshop work for the 2019-2020 academic year was planned to explore the possibilities of public space in this new Urban Regenration operation. The works of the workshop are developed in multidisciplinary teams responding to the previous training of the students.

When the confinement in Spain is decreed in March, we saw almost impossible the development of the planned activities in an online mode. That is why it was decided to vary the topic, focusing it on a Monument to Solidarity Citizenship-which will allow a more individualized approach to work-, but maintaining the territorial reference of the Mercedes-Benz site.

Keywords: Barcelona; Bon Pastor; Citizenship; Solidarity; Monument; Operation Mercedes

\section{Resum}

La pandèmia COVID19 que està causant estralls en la salut pública mundial, ha significat, també, l'adequació- temporal fins al moment- dels procediments de treball en l'ensenyament universitari, tant pel que fa a la impartició de classes com a referent a les activitats a desenvolupar pels estudiants.

La programació de l'assignatura de Taller de Projectes de I'Màster en Disseny Urbà de la Universitat de Barcelona, preveia centrar les activitats projectuals de el taller en què ‘podem anomenar" Operació Mercedes ", un projecte privat de regeneració urbana al barri barceloní de Bon Pastor, que consisteix en convertir $90.000 \mathrm{~m} 2$ de l'antic solar fabril de la Mercedes-Benz, en un complex residencial i d'oficines. 
Segons el Pla General Metropolità (1976) vigent a Barcelona, aquest solar està qualificat com 22a, és a dir "Zona Industrial" i des de 2007, quan Mercedes-Benz deixa d'operar en aquesta fàbrica, configura una de les poques àrees de reindustrialització de Barcelona . La seva venda a el grup inversor Conren-Tramway, a finals de 2018, torna a ressuscitar les pors veïnals sobre l'ús d'aquestes $9 \mathrm{Ha}$.

En el marc de el projecte de recerca HAR2017-88672-R. i dels acords de col·laboració amb l'associació de veïns, des de fa uns anys introduïm temàtiques d'espai públic del territori de Bon Pastor, a l'assignatura "Taller de Projectes" de l'Màster en Disseny Urbà. Dos objectius. El primer explorar idees de solució de problemes d'espai públic amb els estudiants -majoritàriament estrangers-, funcionant el Taller a manera de "Laboratori d'Idees" a el temps que els treballs serveixen de pràctiques n o curriculars. Segon objectiu: aportar idees projectuals als veïns de Bon Pastor per a la gestió i negociació de les diverses accions a desenvolupar al barri.

Per això es va planificar el treball de Taller de el curs 2019-2020 per a explorar les possibilitats d'espai públic en aquesta nova operació de Regenración Urbana. Els treballs de el taller es desenvolupen en equips multidisciplinaris responent a la formació prèvia dels estudiants.

Quan al març es decreta el confinament a Espanya, veiem gairebé impossible el desenvolupament de la feina prevista en un modalitat on-line. És per això que es decideix variar el tema, centrant-lo en un Monument a la Ciutadania Solidària-el que permet una aproximació més individualitzada a la feina-, però mantenint la referència territorial de I'solar del Mercedes-Benz.

Paraules clau: Barcelona; Bon Pastor; ciutadania; solidaritat; monument; operació Mercedes

\section{Antecedentes industriales en el territorio}

El territorio en el que se ubica el barrio del Bon Pastor está situado al Noreste de Barcelona a orillas del río Besòs y dividido entre dos términos municipales (Barcelona y Santa Coloma) producto de la reorganización territorial del Decreto de Nueva Planta de 1716.

Es un territorio rico en terrenos y en agua, río, acequia Condal, diversas acequias (Sant Andreu, Noval, Madriguera...), aguas freáticas. No es de extrañar que dadas estas características a partir de mitad del siglo XIX se convierta en un territorio- junto al de Sant Martí de Provensals- propicio a acoger nuevas industrias, especialmente las más peligrosas y las que requieren de grandes extensiones de terreno.

"Ya desde la etapa manufacturera y después casi en paralelo con la industrialización en el interior de la ciudad se desarrollaron implantaciones fuera muralla dedicadas a parte del proceso productivo textil (blanqueo y acabado)conocido como "ramo del agua", para el que se necesitaban tierras llanas (prados y secaderos) y abundante agua, así como a actividades más nocivas que no tenían cabida en el recinto amurallado, como la elaboración de productos químicos o de fósforos. Otras veces, estas instalaciones estaban condicionadas por el uso de una determinada materia prima, como es el caso de los hornos de cal o especialmente las ladrillerillas, que ocupaban las tierras arcillosas del Llano de Barcelona.

Justo en los años anteriores al derribo de las murallas algunas empresas de mayor envergadura en las que se aplicaban innovaciones técnicas y energéticas buscaron en los municipios de los alrededores de Barcelona espacio y abundancia de agua -pues la que se obtenía en la parte baja del Raval presentaba altos índices desalinidad-para localizar sus nuevos, modernos y grandes recintos fabri- 
les, en especial a partir del año 1846 cuando el ayuntamiento limitó la instalación de nuevas vapores y puso dificultades para la ampliación de las existentes] . Algunos casos son ya conocidos como por ejemplo, hacia 1839 el Vapor del Fil, después el Vapor del Rec y en 1843 la empresa de Ferran Puig (las tres dieron paso posteriormente a conocida Fabra y Coats) en Sant Andreu; el Vidriol en Les Corts desde poco antes de 1839; el Vapor Vell, asentado en Sants(1844-1846) y la España Industrial entre 1847-49 también en Sants; el de Vilaregut (1837) y el de Puigmarti (1839) en Gracia, y el de la Auxiliar de la Industria en 1853-55 en terrenos de Nuestra Señora del Portcerca del Canal de la Infanta, pertenecientes a la Marina de Sants" (Tatjer, Mercè 2006)

En el área que ocupa el Bon Pastor debemos señalar que primero se instalan las industrias y, posteriormente, empiezan a crecer los núcleos residenciales (Checa, Martí; Travé, Carme 2007, 200; Checa i Artasu, Martí 1999; Checa i Artasu, Martí; Xavier Basiana 2000)

Como es bien conocido el Plan de Reforma Interior y Ensanche de Barcelona de Ildfons Cerdà se estructuraba, en muy buena medida, a partir de una teoría de vialidad que incorporaba las estructuras ferroviarias existentes. En su plano topográfico inicial sólo existía la línea de Granollers. En ediciones posteriores que trabajan sobre el plano cartográfico de Cerdà, aparecerá ya la línea de Zaragoza.

Las anexiones del 1897 y posteriores representan un impulso a la industrialización del área del Besòs, especialmente a partir del plan de Enlaces de Jaussely (1903-1907). Aunque el proyecto nunca se llevó a cabo, una versión simplificada del mismo es el Plano de Urbanización de Barcelona (1917). Este plan concreta un esquema general del modelo de Jaussely. Fue realizado conjuntamente por la Oficina Municipal de Urbanización, dirigida por Pere Falqués y Ezequiel Porcel, y por el arquitecto Ferrán Romeu.

Su génesis es el programa elaborado en 1914 por una ponencia municipal, producto de la iniciativa de la Liga Regionalista, hegemónica a partir de este año en el ayuntamiento de Barcelona, y formada por Manuel Vega y March, Guillem Busquets, Jaume Bofill i Mates y Josep M. de Lasarte. El plano, establece la red viaria básica de Barcelona (articulada por los cinturones de ronda), el sistema de parques, la limitación del crecimiento según el modelo de la manzana Cerdà, la creación del nuevo centro urbano en el eje plaza de España-plaza de Barcelona (Diagonal-Urgell-carretera de Sarriá). El esquema del plan estuvo vigente hasta la aprobación del plan comarcal de 1953.

Una de las consecuencias de este plano de urbanización consistió en la introducción de unas primeras normas de "zonificación" en las Ordenanzas Municipales de 1927. Estas normas han influido a lo largo del tiempo en los posteriores Planes de ordenación de Barcelona $(1953,1976)$ y facilitará la instalación de nuevas factorías en el sector industrial de Sant Andreu (Checa i Artasu, Martí; Gimeno Barona, Pilar. 1998). Incluso, el Plan Macià de 1934, estipula el futuro de Sant Andreu como sector industrial. 

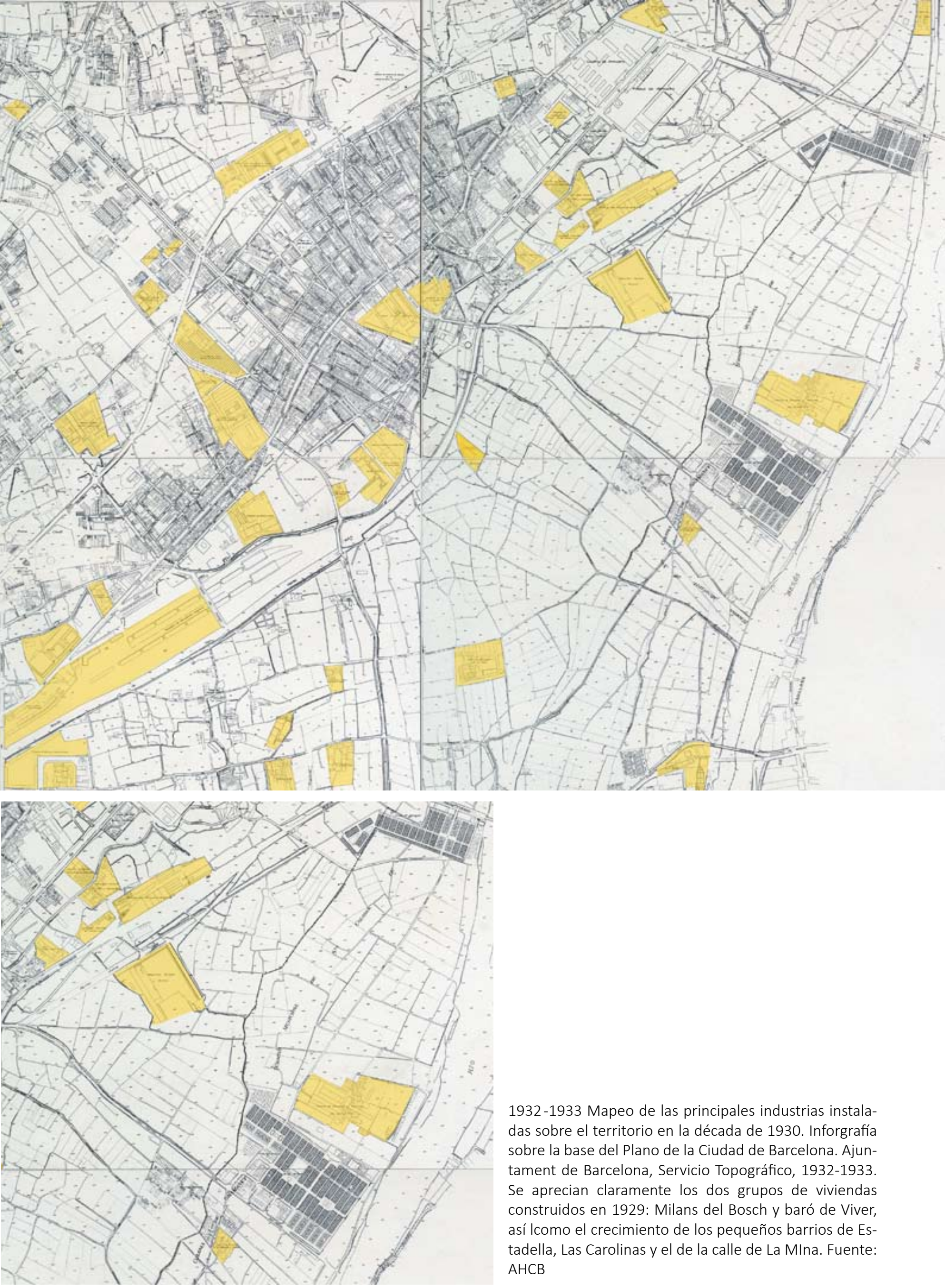

1932-1933 Mapeo de las principales industrias instaladas sobre el territorio en la década de 1930. Inforgrafía sobre la base del Plano de la Ciudad de Barcelona. Ajuntament de Barcelona, Servicio Topográfico, 1932-1933. Se aprecian claramente los dos grupos de viviendas construidos en 1929: Milans del Bosch y baró de Viver, así Icomo el crecimiento de los pequeños barrios de Estadella, Las Carolinas y el de la calle de La MIna. Fuente: AHCB 


\section{Consolidación del destino industrial}

Durante la guerra de España, muchas empresas del territorio, entraron a formar parte del "ramo de la guerra" y a producir material bélico para la República. Dado su papel estratégico, muchas de ellas sufrieron bombardeos por parte de la aviación italiana que tuvieron efectos colaterales en la población residente, como los de 1937 en Bon Pastor y en Santa Coloma.

Tras la contienda, el gobierno de Franco crea el INI (Instituto nacional de Industria) al que, paulatinamente, se incorporan algunas de las grandes empresas radicadas en Sant Andreu. En 1946 se crea ENASA (Empresa Nacional de Autocamiones S.A.), absorbiendo las instalaciones de la Hispano Suiza en la Sagrera e inicia la producción de los camiones Pegaso. El 27 de diciembre de 1951 se firmó con el Estado español la nacionalización de la antigua Elizalde arguyendo razones de Defensa Nacional, para formar parte del INI, y continuar construyendo motores de aviación, con las necesarias modernizaciones. Se constituye la empresa ENMASA (Empresa Nacional de Motores de Aviación, S.A.). Esto conllevó el traslado de la fábrica Elizalde desde el Paseo de San Juan, al barrio del Bon Pastor, junto a las instalaciones de La Maquinista.

"La fábrica estatal de ENMASA tuvo una corta vida. Fundada en 1951, y con el conjunto industrial listo y en funcionamiento a partir de 1957, ya en 1959 la fábrica empieza la fabricación de motores para automóviles con licencia Daimler-Benz. En 1963 pasa a producir furgonetas Mercedes-Benz, y en 1968 se fusiona con IDASA, el importador en España del resto de las licencias Mercedes-Benz, produciendo también motores SEAT. En 1972 se dedica a producción solamente de motores de automóviles y finalmente, en 1981, como consecuencia del acuerdo firmado ente el Instituto Nacional de Industria y Daimler-Benz, pasa a denominarse Mercedes-Benz España, S.A". (Agostini, F 2015)

La Maquinista Terrestre y Marítima también entra a formar parte del conglomerado de empresas del INI.

Entre los años 1940 a 1960 se ponen en marcha diversos planes que afectarán de modo importante al destino industrial de la zona. El plan ferroviario de 1944 que es continuación del plan republicano de 1933, consolidará tanto el soterramiento de vías en la actual Avenida Meridiana, como la creación de un ramal entre Sant Andreu y el litoral que consolidará el denominado "triángulo ferroviario" y potenciará el corredor ferroviario de La Sagrera.

"Posteriorment al pla de 1953, l'any 1966, es va produir una revisió més important del Pla d'Enllaços Ferroviaris. Es proposen dues grans estacions teminals en les àrees de la Sagrera i de Sants, i se suprimeix la via entre l'estació de França i el Besòs, i el complex d'estacions de càrrega del Poblenou i el Bogatell. D'aquesta manera es comencen a crear unes noves condicions de permeabilitat que permetran la urbanització residencial d'aquesta área".(Torres Capell, Manuel de 1999, 218)

Es a inicios de la década de 1940 que se procede a las negociaciones para la anexión del área de Santa Coloma situada en el margen derecho del río Besòs, anexión que ya será efectiva a inicios de 1945. Esta anexión permite crear un gran territorio que tanto el "Plan General de Ordenación Urbana de la provincia de Barcelona" (1947) como el posterior "Plan Comarcal de ordenación ur- 
bana de Barcelona" (1953) definirán claramente como uno de los grandes territorios industriales de Barcelona. Tanto el "Plan director del Área Metropolitana de Barcelona" (1966) como el "Plan General Metropolitano" (1976) - todavía vigente- mantendrán la calificación de suelo industrial para una gran porción de los solares de esta zona.

Como derivación del Plan Comarcal de 1953, se redacta, en 1955, un "Plan Parcial de Ordenación del sector limitado por la línea del FF.CC., paseo de Santa Coloma, Río Besòs y prolongación de la calle Aragón" que dará forma, casi definitiva al conjunto de polígonos industriales que rodean los barrios de Baró de Viver y Bon Pastor y que, en la actualidad, suponen la mayor reserva de suelo industrial en Barcelona tras la adaptación de las zonas del Poblenou al concepto 22@.(Santamaria Concha, José A. 2018)

El crecimiento industrial estimado de la zona, vino acompañado de un crecimiento residencial, especialmente a partir de 1959 con la promulgación del "Plan de Urgencia Social de Barcelona" que suponía un crecimiento substancial de nuevas viviendas en Baró de Viver, Bon Pastor y vía Trajana- Rambla Prim (Sant Martí de Provençals). Este enorme crecimiento no estuvo acompañado del crecimiento de servicios urbanos (sanitarios, transporte público) ni de la mejora en la urbanización de las calles de los polígonos y barrios de la zona. (Checa, Martí; Travé, Carme 2007; Angosto, Salvador 2019 )
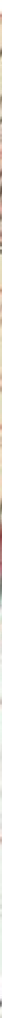

Década de 1950.

El desarrollo del plan provincial de Barcelona recogerá la idea de los procesos anteriores de convertir a Sant Andreu y, más concretamente, a Bon Pastor en una gran reserva de suelo industrial, para grandes y medianas empresas. Esta política se concretará en el Plan Comarcal (de Ordenación de Barcelona y de su Comarcal) de 1953.

Fuente: AA.VV del Bon Pastor / CR POLIS. Exposición “Bon Pastor un territorii canviant, 2020 


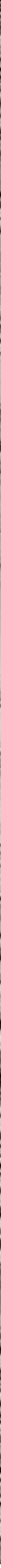

1947 Distribución de las grandes empresas instaladas en el territorio. Infografía sobre fotos del vuelo de C.E.T.F.A. (Compañía Española de Trabajos Fotográmetricos Aéreos). Fuente: ICGC. Col-leccio digital: Fotoplànols de ciutats catalanes (1945-1966), http://cartotecadigital.icc.cat 
1955 Plan Parcial de Ordenación del sector limitado por la línea del FF.CC., paseo de Santa Coloma, Río Besòs y prolongación de la calle Aragón.

Consolidación de los polígonos industriales en el territorio

Fuente: . Registre de planejament urbanístic de Catalunya

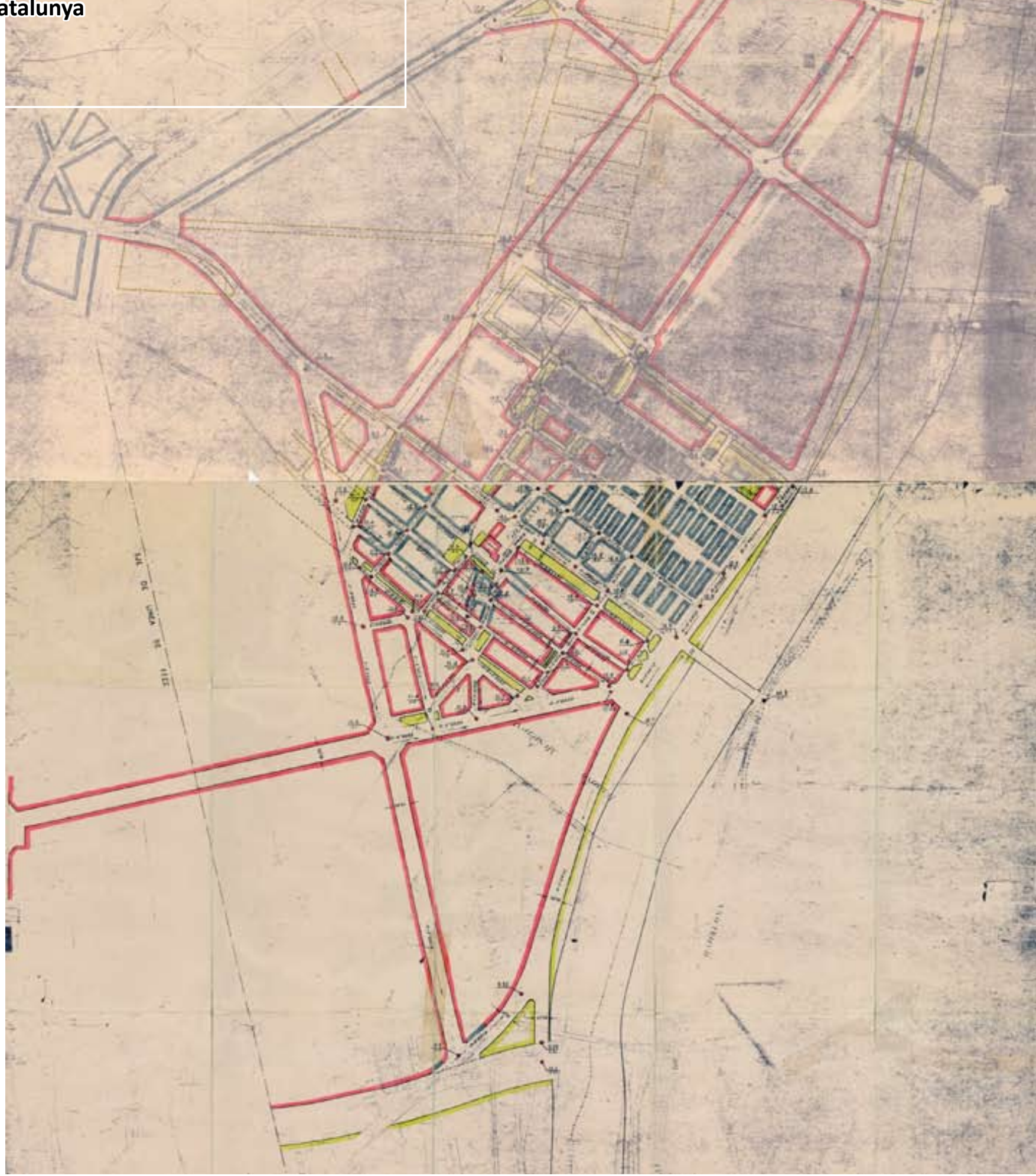




\section{1}

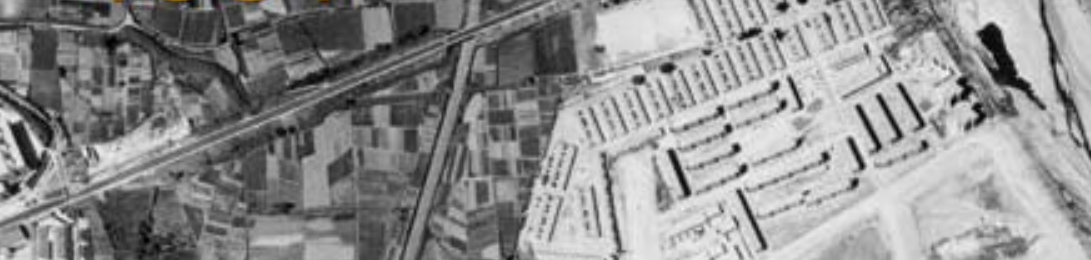

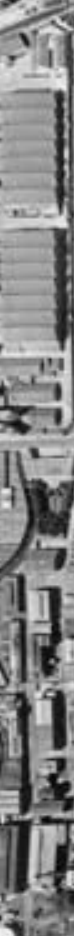

A

ais
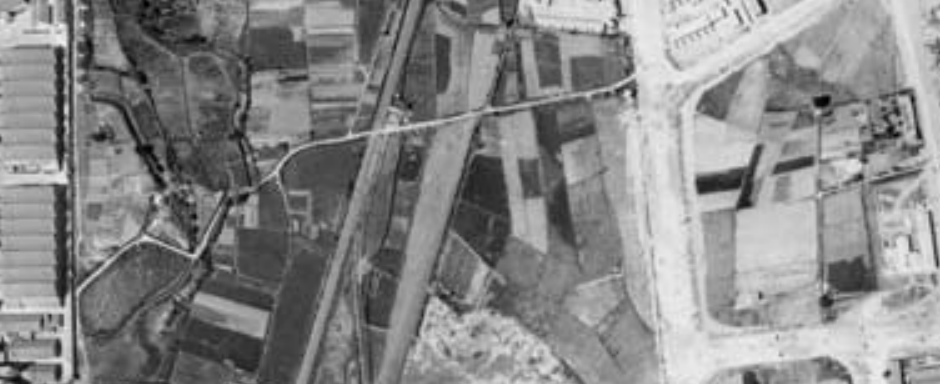

in.

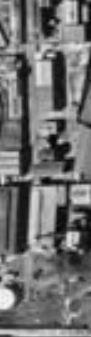
ing.

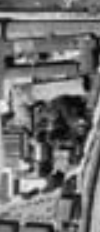
(5)

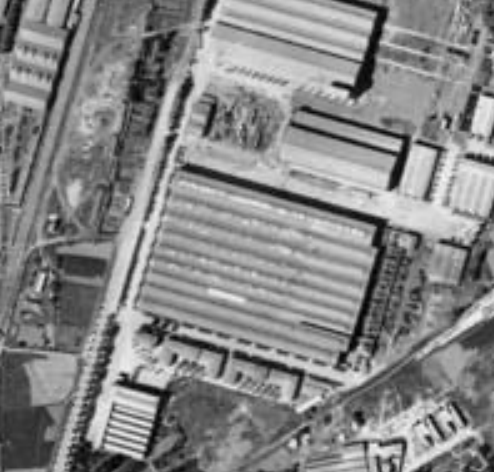

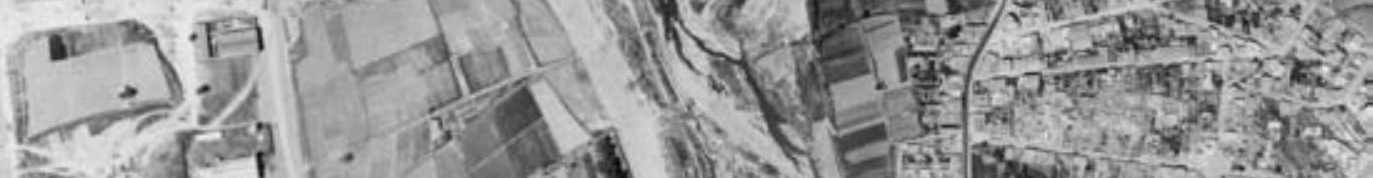<smiles>[SiH2]=[As]</smiles><smiles>[AlH2]</smiles>

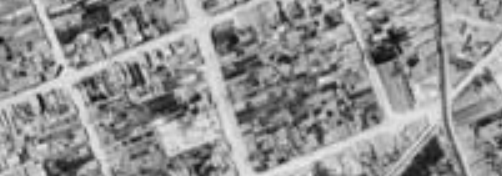

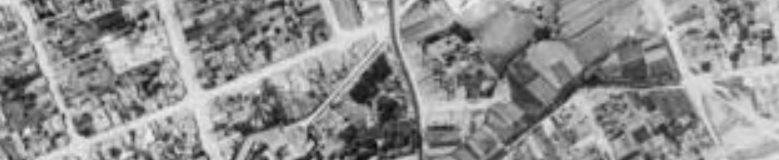

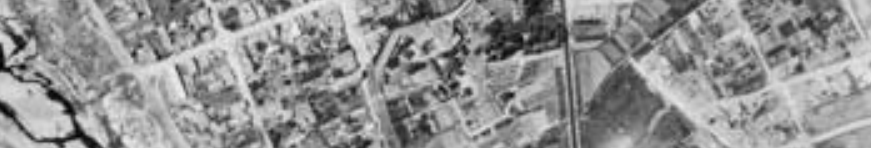

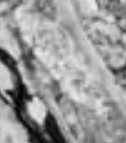

ines

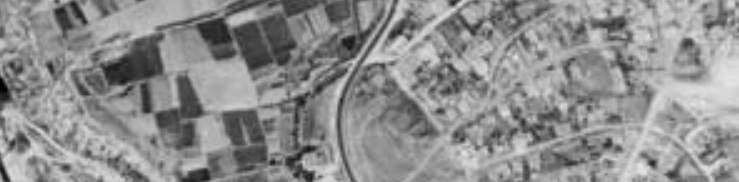

$7 a_{1}$ Net ${ }^{2}$.

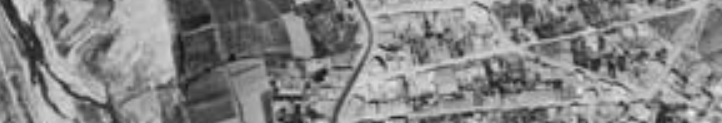

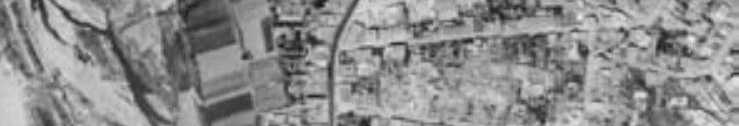

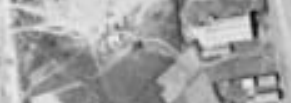
(x) 5 ing

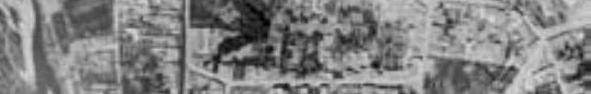

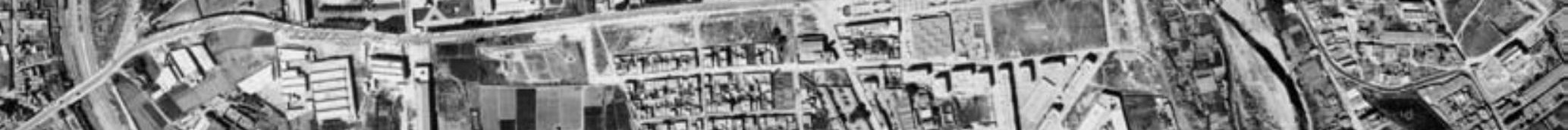

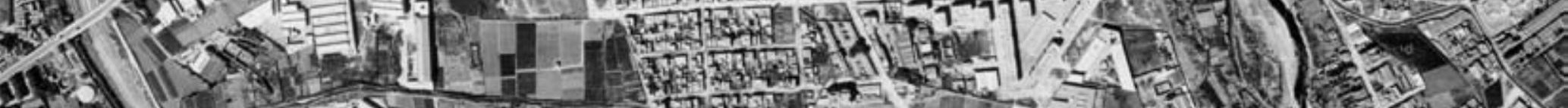

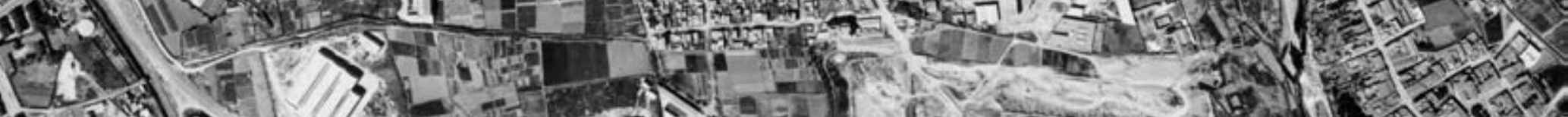

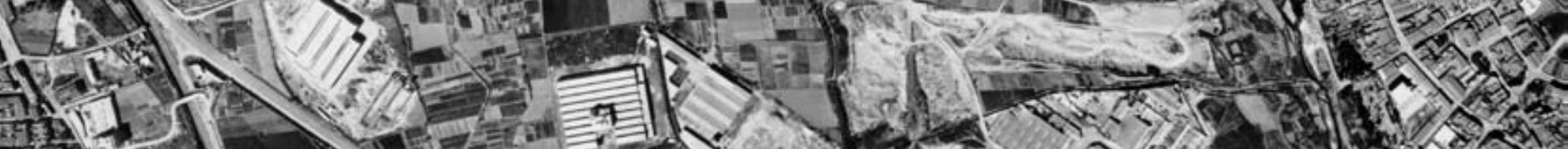
1 he (1)
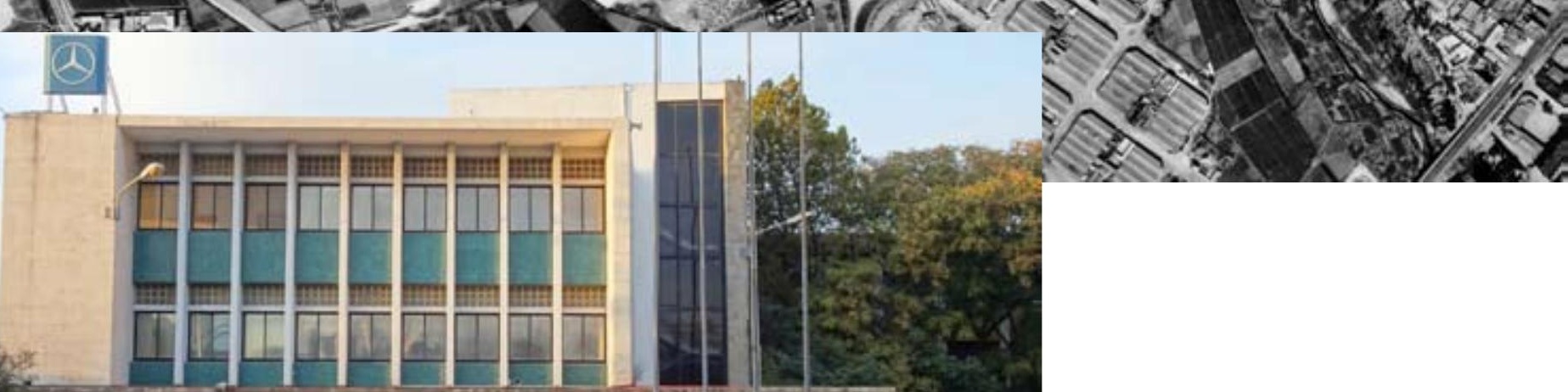

s.t.
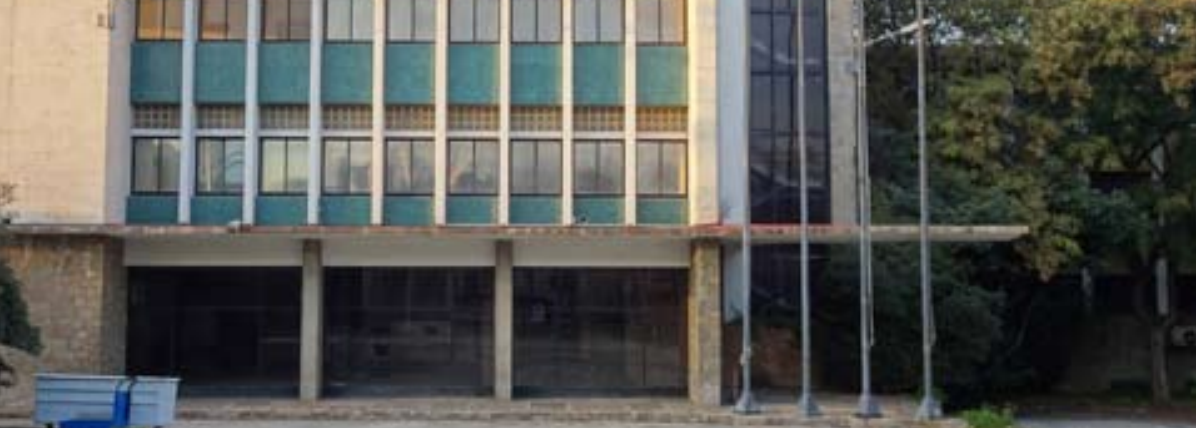

Fábrica ENMASA - Merce-

des Benz. 1950-1957. Au-

tores: Robert Terradas Via

y Vicente Alegre

Datos: DOCMOMO Ibérico 


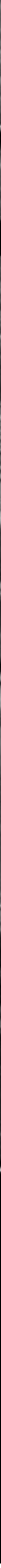

1962 Foto del vuelo SACE (Servicios Aéreos Comerciales Españoles); Rodríguez Escalona, Carlos. Fuente: ICGC. Col-leccio digital: Fons SACE , http://cartotecadigital.icc.cat, http://cartotecadigital.icc.cat 


\section{Gestionar la obsolescencia}

La propuesta de eliminación de las vías férreas del litoral, facilita la necesidad de revisar las directrices del Plan Comarcal (1953) refrentes a algunas zonificaciones industriales. El argumento evidente era la necesidad de trasladar industrias casi centenarias y, por tanto, obsoletas, a otros espacios industriales más modernos como el de la Zona Franca y a diversos polígonos industriales que iban creciendo alrededor de la incipiente red de autopistas. Se inician una serie de movimientos de los propietarios de las grandes industrias del Poblenou para que, aprovechando mecanismos legales del Plan de 1953, se procediera a la recalificación de grandes terrenos industriales. En 1965 se publica un folleto, costeado por los grandes industriales, con el título "Barcelona, una ciudad que no puede seguir viviendo de espaldas al mar" (Bonet Castellana, A 1965; Berri, André 2018)

"Los promotores del plan fueron las empresas Maquinista Terrestre y Marítima S.A., Materiales y Obras S.A (Macosa), Catalana de Gas i Electricidad S.A., Créditos y Docks S.A., Foret S.A, e Hidroeléctrica de Cataluña S.A. Todos juntos, asociados en una entidad mercantil Ilamada "La Ribera S.A.", de la cual eran entusiastas gerentes los entonces jóvenes prometedores ejecutivos Miquel Roca i Junyent y Narcís Serra i Serra.(...)

"El plan de la Ribera fue aprobado inicialmente por el Ayuntamiento de Barcelona el 13 de agosto de 1970, cambiándole el nombre por el de "Sector Marítimo Oriental", y eliminación de las vías del litoral reduciendo su ámbito para evitar el traslado de una serie de pequeñas industrias, comercios y viviendas que afectaban 30.000 personas". (FAVB-Federació de Veins de Barcelona-1997)

Sin embargo, Comisión de Urbanismo, enfrascada en el redactado del Plan General Metropolitano, consideró oportuno no aprobar.

Este plan afectaba de lleno a la Barceloneta y a los sectores residenciales del Poblenou. La defensa de estos barrios supuso la emergencia de movimientos sociales urbanos muy importantes ((Domingo, Miguel -Bonet, M.R 1998). El proyecto estaba asociado con los primeros intentos de remodelación del Port Vell de la ciudad y de la creación de un nuevo barrio residencial en la falda oriental de la montaña de Montjuic (Echenique, Marcial 1965). Indirectamente, afectaba, también, al territorio que estamos estudiando, en primer lugar, al dar preeminencia a las instalaciones ferroviarias de La Sagrera y en segundo lugar porqué este nuevo plan, afectaba a los planes de metro. Concretamente en 1963 «Plan de desarrollo de la red subterránea de Transporte colectivo de Barcelona» planteaba el trazado de metro por el interior del Poblenou, subiendo en paralelo al río Besòs, hasta La Pau, los polígonos industriales del Besòs, Bon Pastor y Baró de Viver.

Estos ideas de cambio, iban acompañadas de otras operaciones como la presentación de la candidatura de Barcelona (1968) para acoger los Juegos Olímpicos de 1976 y la candidatura de BarceIona (1969) para organizar la EXPO de 1982. Tanto los JJ.OO como la EXPO iban a realizarse en la zona de Collserola, mirando al Vallé. Muchas de estas ideas se resumieron en un plan "utópico" del alcalde Porcioles, presentado a inicios de 1970, bajo el lema "Barcelona 2000" que contemplaba el desarrollo del Plan de La Ribera, los cinturones de ronda y los túneles del Tibidabo. 


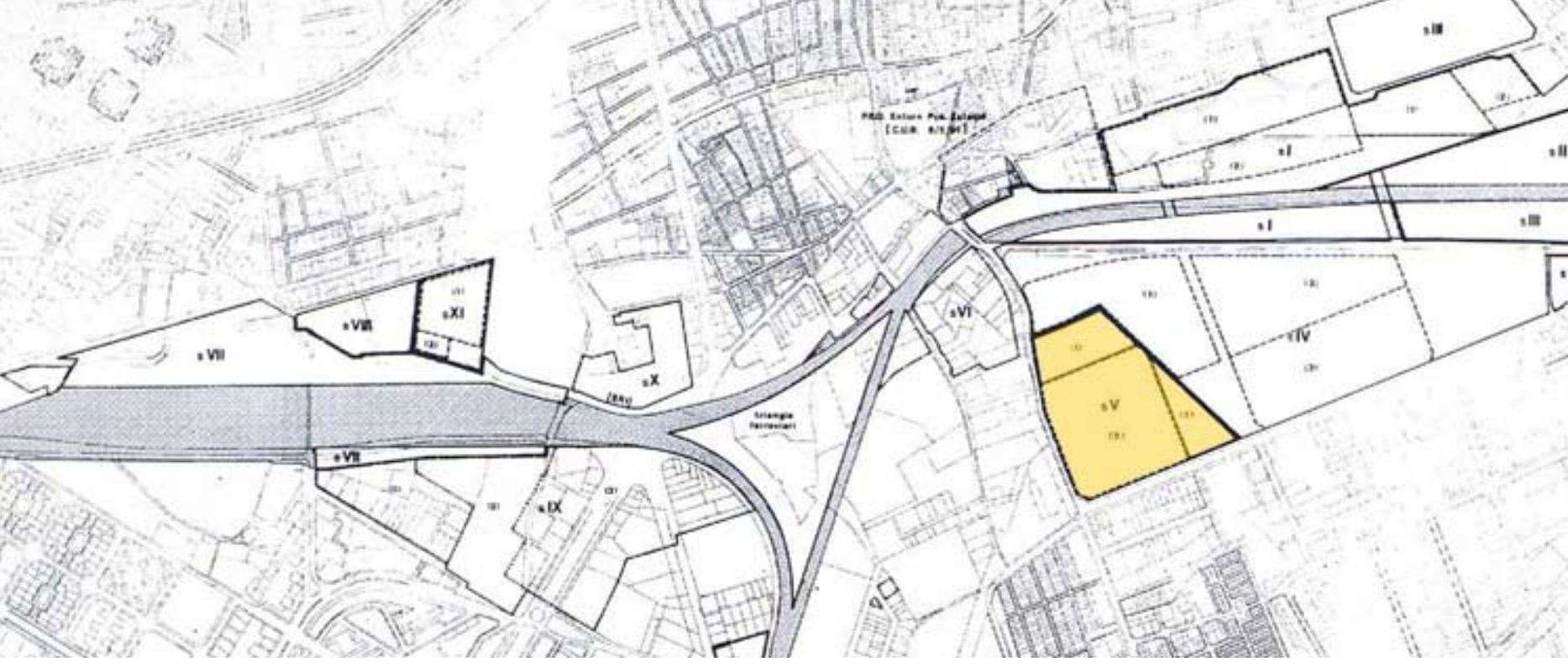

Primer avance de la MPGM Sagrera- Sant Andreu, en el que observamos que el solar de Mercedes está contemplado como sector $V$ de la operación. (Tajadura, J.A. et al. 1996)

tintos planes que afectan a la remodelación del sector de Sant Andreu-Sagrera. Por ello plantea una Modificación de Plan General Metropolitano (MPGM) para el sector que incluye la creación de la nueva estación central de Barcelona, la puesta en marcha de varios proyectos edificatorios de vivienda y la reordenación de los terrenos de La Maquinista mediante la iniciativa privada que supondrá [1] la creación del Centro Comercial La Maquinista y [2] la construcción de la llamada "Residencial La Maquinista". Estas modificaciones legales implican la modificación de la clave 22a (suelo industrial) por la clave 22 (industrial, terciario, servicios y comercial) y por las claves 18 (zona edificación volumétrica) y $6 b$ (parques y jardines de nueva creación) lo que permite proceder a la operación de transformación urbana.

A pesar de que la factoría de Mercedes-Benz está todavía operativa, un primer redactado de la MPGM la incluye como sector a remodelar (Tajadura, J.A. et al. 1996). Sin embargo, el dictamen de aprobación definitiva de la MPGM del Departamento de Política Territorial i Obra Públicas de la Generalitat de Catalunya, en su artículo quinto, excluye de la modificación los terrenos ocupados por la factoría Mercedes, el sector del Torrent de l'Estadella y el sector industrial afectado por la prolongación de la calle ciudad de Asunción (Ajuntament de Barcelona 1997).

El centro comercial de La Maquinista inicia actividades en el año 2000 y en los tres años posteriores se construyen las viviendas de "Residencial La Maquinista".

Mercedes no planteará el cierre de la planta hasta el 2007. La dirección de Mercedes Benz anuncia a sus 420 trabajadores el cierre de esta planta y la externalización de la producción a tres proveedores diferentes, con la idea de recolocar a 258 de ellos en una nueva empresa, la DaimlerEstampaciones Sabadell, ubicada en Esparraguera. El resto pueden optar por jubilaciones anticipadas o el traslado a la fábrica de Vitoria.

Desde un primer momento, los sindicatos creen que la decisión de la empresa no responde a razones industriales sino a una operación de especulación urbanística, para obtener importantes plusvalías de las actuales instalaciones del barrio de Sant Andreu, ya que están en una zona de gran desarrollo urbanístico y tienen la operación La Maquinista- Almston como referente. Este 
cierre de planta industrial se produce, precisamente, cuando las consultoras internacionales avisas de la falta de suelo industrial en Barcelona cuya demanda se desacelera del $10 \%$ al $2 \%$ debido al alza de precios. En diciembre de 2007, El País, anuncia que las antiguas instalaciones de Mercedes albergarán 1.000 pisos protegidos de una operación con un total de 1.500 viviendas (Redacción Barcelona 2007).

En aquellos momentos el Ayuntamiento de Barcelona, ante la escasez de suelo para construcción de vivienda pública, estaba estudiando distintas fórmulas para estudiar el futuro de una parte de los suelos calificados 22a en el PGM de 1976, proponiendo la densificación, renovación y transformación de determinadas áreas de Barcelona para abordar la demanda de viviendas y techo para nuevas actividades productivas que mantenga el equilibrio del mercado de trabajo. La motivación de afrontar estas transformaciones se formula en base a cuatro argumentos de reflexión, la industria en Barcelona, las necesidades de vivienda, las nuevas formas productivas y la estrategia territorial de desarrollo de Barcelona, dentro del marco metropolitano.(Ajuntament de Barcelona 2004)

En este marco y ante la presión mediática, sindical y barrial- según Paquita Delgado, presidenta de la Asociación de vecinos de Bon Pastor, es preciso «mantener el máximo de tejido industrial» en la zona. Por un lado, porque «emplea a todos los barrios de alrededor» y, por otro, porque está ligado a la identidad de estos barrios-, el Ayuntamiento a redacta un documento de orientaciones ante la expectativa de que, realmente, se produzca una operación de especulación inmobiliaria.

Según este documento, las nuevas actividades productivas permiten estimular la combinación de usos urbanos, creando espacios de mezcla con las actividades comerciales, de oficinas o residenciales, en la línea de algunas iniciativas que ya se están desarrollando en la ciudad. Desde comienzos de los noventa hemos ido asistiendo a la introducción en el campo del urbanismo del concepto "actividades productivas", frente a la clásica denominación de "usos industriales", como expresión más general de todas las actividades que tienen que ver con el proceso productivo. Se utilizan nuevas fórmulas más flexibles para definir el uso característico en una determinada área que deberán ser concretadas por el planeamiento, y se rehúye de la anterior enumeración de actividades permitidas y prohibidas, como de hecho todavía encontramos en el PGM vigente desde 1976. La clasificación decimonónica sobre usos admitidos, compatibles o no admitidos ha sido sustituida por los criterios de la Ley de Intervención Integral de la Administración Ambiental (1998).

Para proceder a regular los posibles usos de esta gran parcela y considerando que cabe tanto la posibilidad de reutilización industrial, como destinarla a funciones urbanas más complejas que incorporen residencia y actividad económica, se plantea la ordenación de usos y edificabilidad resumida en la tabla siguiente (Ajuntament de Barcelona 2007).

En paralelo los grupos de PSC, ERC e ICV-EUiA presentan una propuesta de resolución en el Parlament emplazando al gobierno catalán a no autorizar la recalificación de los terrenos de la fábrica y que obligue a la empresa a no efectuar ningún proceso de realización de estos activos inmobilia- 


\section{1. ÀMBIT}

Superficie

$106.184 \mathrm{~m}^{2}$

\section{EDIFICABILITAT}

Index d'edificabilitat brut

Sostre (per aplicació de l'index)
$1,63 \mathrm{~m}^{2} \mathrm{st} / \mathrm{m}^{2} \mathrm{sdl}$

sup.àmbit index brut

$\begin{array}{llll}106.184 & 1,63 & 173.080 & \mathrm{~m}^{2} \text { st }\end{array}$

\section{DISTRIBUCIÓ DE SOSTRE PER USOS}

\begin{tabular}{|c|c|c|c|}
\hline Sostre residencial & & \multirow[t]{2}{*}{$70 \%$} & \multirow[t]{2}{*}{$121.156 \mathrm{~m}^{2} \mathrm{st}$} \\
\hline nombre d'habitatges & 1.514 unitats & & \\
\hline Sostre per activitats econòmiques & & $30 \%$ & $51.924 \mathrm{~m}^{2} \mathrm{st}$ \\
\hline TOTAL & & $100 \%$ & $173.080 \mathrm{~m}^{2} \mathrm{st}$ \\
\hline
\end{tabular}

\section{USOS DEL SÒL}

\section{Sistemes minims en compliment d'estandards legals}

$\begin{array}{lcc}\text { Vialitat } & 30 \% & 31.855 \mathrm{~m}^{2} \\ \text { Equipaments } & 9 \% & 9.087 \mathrm{~m}^{2} \\ 7,5 \mathrm{~m}^{2} \mathrm{sol} / 100 \mathrm{~m}^{2} \text { sostre residencial } & & \\ & & \\ \text { Espais lliures } & 21 \% & 22.068 \mathrm{~m}^{2} \\ 15 \mathrm{~m}^{2} \text { sol } / 100 \mathrm{~m}^{2} \text { sostre residencial } & & 18.173 \\ 7,5 \mathrm{~m}^{2} \mathrm{sol} / 100 \mathrm{~m}^{2} \text { sostre ac.economiques } & & 3.894\end{array}$

Total sistemes minims

Zones màximes

TOTAL

$100 \% \quad 106.184 \mathrm{~m}^{2}$

\section{EDIFICABILITAT NETA}

Sostre

Zones màximes

Index d'edificabilitat net

\section{HABITATGE}

\begin{tabular}{|c|c|c|c|}
\hline \multirow[b]{2}{*}{ Habitatge lliure } & \multicolumn{2}{|c|}{ Sostre } & Núm.habitatges \\
\hline & $35 \%$ & $42.405 \mathrm{~m}^{2} \mathrm{st}$ & 530 \\
\hline Habitatge de protecció & $65 \%$ & $78.751 \mathrm{~m}^{2} \mathrm{st}$ & 984 \\
\hline Preu concertat & $32,5 \%$ & 39.375 .5 & 492 \\
\hline Règim general & $32,5 \%$ & $39.375,5$ & 492 \\
\hline
\end{tabular}

TOTAL
$173.080 \mathrm{~m}^{2} \mathrm{st}$

$43.174 \mathrm{~m}^{2}$

rios, sino que se destinen completamente (los ingresos por la venta del terreno) a la financiación de un proyecto industrial propio que permita mantener el nivel de empleo industrial pactado con la representación de los trabajadores. En aquel momento la prensa económica estimaba que Mercedes-Benz podría obtener 400 millones de euros por esta operación.

Tras unos meses agitados y con desmentidos constantes, las actuaciones sobre el solar de La Mercedes quedan en stand by. Aunque a partir de 2011, con el gobierno de CIU, parece que se producen algunas conversaciones con la compañía alemana, planteando la reutilización de la planta. Las ideas pasan desde la instalación de una Escuela de Formación Profesional vinculada con el mundo de la automoción, hasta la posibilidad de implantar un Museo del Automóvil. Ningún proyecto concreto hasta que en 2018 se vuelven a activar las alarmas sobre posibles usos y posible especulación con los terrenos. 


\section{MERCEDES BON PASTOR}

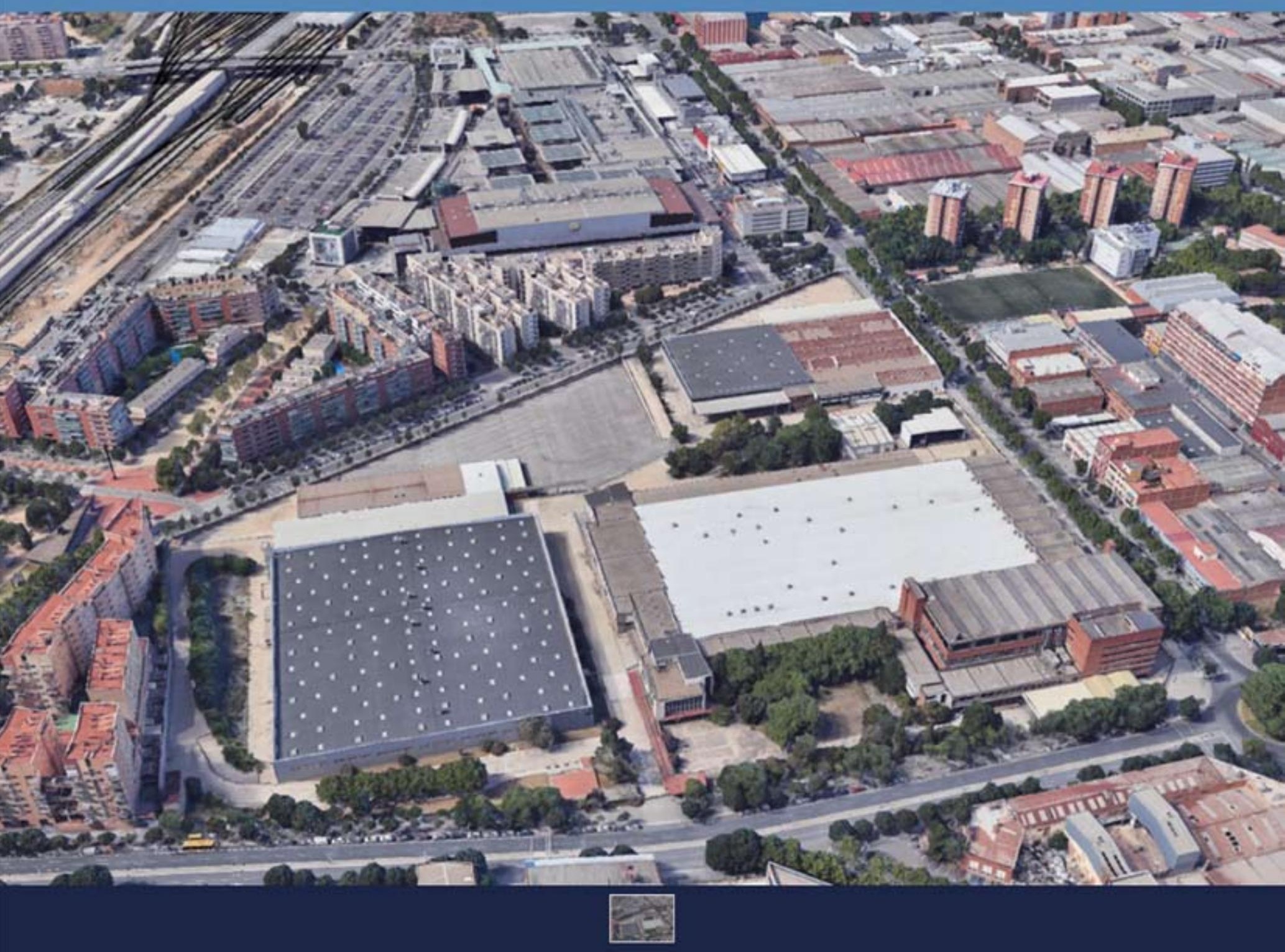

Acquired from Mercodes-Benz España S.AU, its old factory in the Sant Andreu district of Barcelona. This factory had more than 100 years of industrial activity. The site on which Mercedes -Benz's manufacturing faclitiles were located has a surface area of $90,000 \mathrm{~m} 2$ in a privileged setting between the historic centre of Sint Andreu, the shopping centre of La Maquinista, the future Parc del Cami Comtal and the Bon Pastor district. This area of Barcelona is undergoing a deep transformation with the excution of the La Sagrera - Sant Andreu public investment project, within the Barcelana Metropolitan Strategic Plan that promotes the sustalnable urban development of 164 hectares of the city. The future real estate development of this unique site will be the subject of in depth analysis by Conren Irarmary, its architects and its urban planning advisors in the coming months.
Project typecurban regeneration

> Location Carrer de Sant Adria S5 - Barcelona

> Size: 90,000 sqm

\section{"Operación Mercedes"}

A finales de 2018, la compañía de inversiones inmobiliarias, ConrenTramway- con un capital mixto catalán y alemán- anuncia que ha adquirido

"a Mercedes-Benz España S.A.U. su antigua fábrica en el barrio de Sant Andreu de Barcelona. Esta fábrica tenía más de 100 años de actividad industrial. El solar en el que se ubicaron las instalaciones de fabricación de Mercedes-Benz tiene una superficie de $90.000 \mathrm{~m} 2$ en un entorno privilegiado, entre el casco histórico de Sant Andreu, el centro comercial de La Maquinista, el futuro Parc del Camí Comtal y el barrio del Bon Pastor. Esta zona de Barcelona está experimentando una profunda transformación con la ejecución del proyecto de 
inversión pública La Sagrera - Sant Andreu, dentro del Plan Estratégico Metropolitano de Barcelona que promueve el desarrollo urbano sostenible de 164 hectáreas de la ciudad. El futuro desarrollo inmobiliario de este sitio único será objeto de un análisis en profundidad por parte de Conren Tramway, sus arquitectos y sus asesores de planificación urbana en los próximos meses".

Califican esta operación como una operación de "regeneración urbana" sobre una superficie de $90.000 \mathrm{~m} 2$ y con un coste que, según la prensa económica, podría oscilar entre los 50 y los 100 millones de euros (Granda, Manu 2019).

Tras las elecciones municipales de 2019, ConrenTramway realiza una primera reunión con distrito y vecinos, donde exponen de modo muy somero sus ideas sobre la operación que comportarán la implementación de oficinas y de nuevas viviendas. Seguramente, a lo largo del 2019 habrán tenido lugar otras reuniones con diversos representantes municipales, puesto que el proyecto no puede avanzar sin una reacalificación de los terrenos, es decir una Modificación del Plan General Metropolitano (MPGM). No tenemos noticia de estas reuniones. En enero de 2020, la regidora del distrito, representantes del MUHBA (Museo de Historia de la Ciudad) y vecinos realizan una visita al complejo. Esta visita es debida a que el edificio de Terradas, debería considerarse como patrimonial, y al hecho de que Distrito y vecinos, consideran oportuno mantener el edificio, como equipamiento, sino en su totalidad por lo menos en parte.

Tras esta visita se inician las obras de derribo de naves y de excavación de los terrenos. La pandemia las detendrá momentáneamente, pero hoy en día están prácticamente finalizadas.

La operación Mercedes, tome la forma que tome, es una operación de regeneración muy importante para el barrio del Bon Pastor. En primer lugar, esta operación ocupa un lugar de "centro" en relación a distintas actuaciones que se están desarrollando. Un diseño adecuado del espacio y de las nuevas construcciones puede activar la relación y conexión entre las dos partes del territorio (Bon Pastor histórico y Residencial La Maquinista) que, hoy en día prácticamente son inexistentes, puesto que el propio solar hace de barrera entre territorios. La adecuada solución de esta centralidad permitirá, además, la conexión con la zona de "Colorants" y Sant Andreu. Obviamente, manteniendo la actividad "industrial" es un factor que garantiza oportunidades de empleo en la zona -idealmente bajo la idea de justicia de género- y, dependiendo del tipo de "industrias" a instalar -orientadas a la economía circular-, una contribución a la su sostenibilidad del territorio.

La activación de la "operación Mercedes" nos llevó a discutir con la Asociación de Vecinos del Bon Pastor, la pertinencia de que el Centro de Investigación Polis, junto a investigadores del CRIT (Grupo de investigación Creatividad, Transformación Urbana, iniciara una serie de estudios sobre las posibilidades que el solar de la Mercedes podía ofrecer como espacio público articulador entre territorios. 


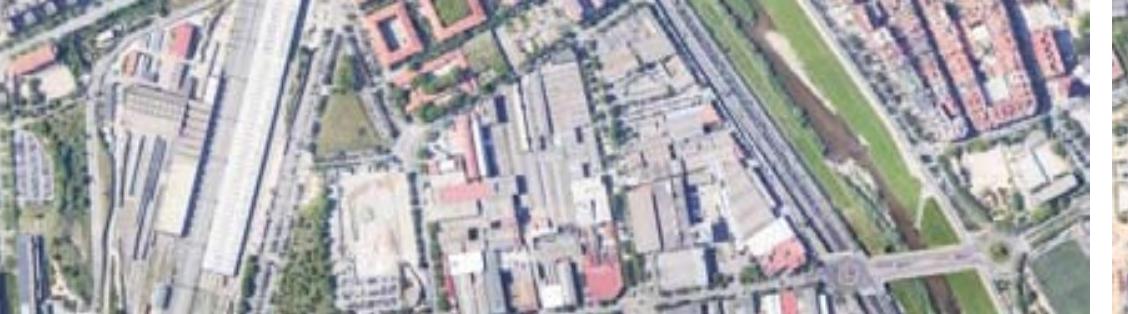




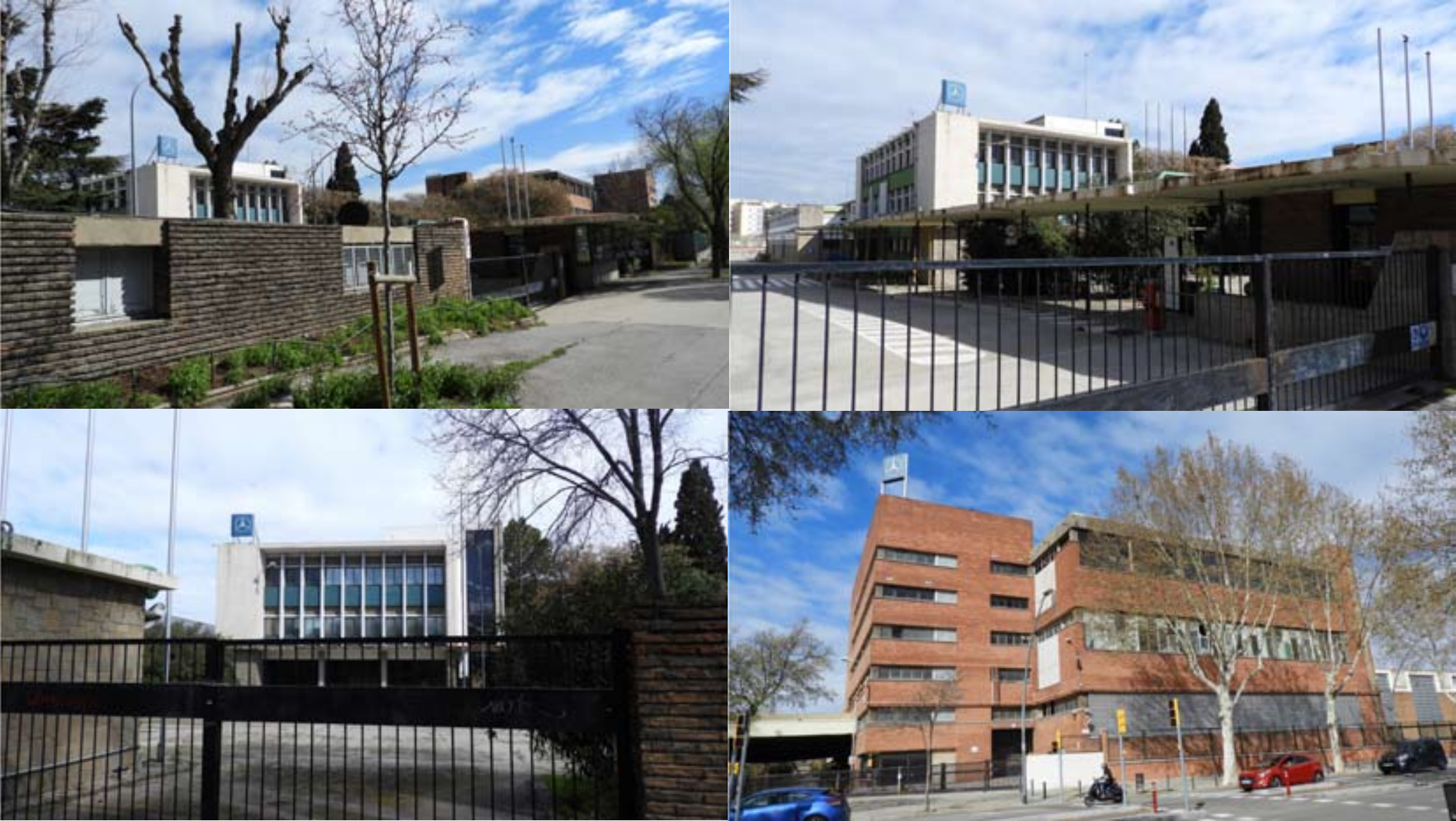

Los edificios que se pretenden conservar obra de Robert Terradas Via y Vicente Alegre

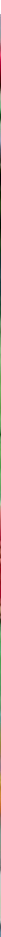

Interior de una de las naves a preservar. Fuente: Archivo Salvador Angosto 


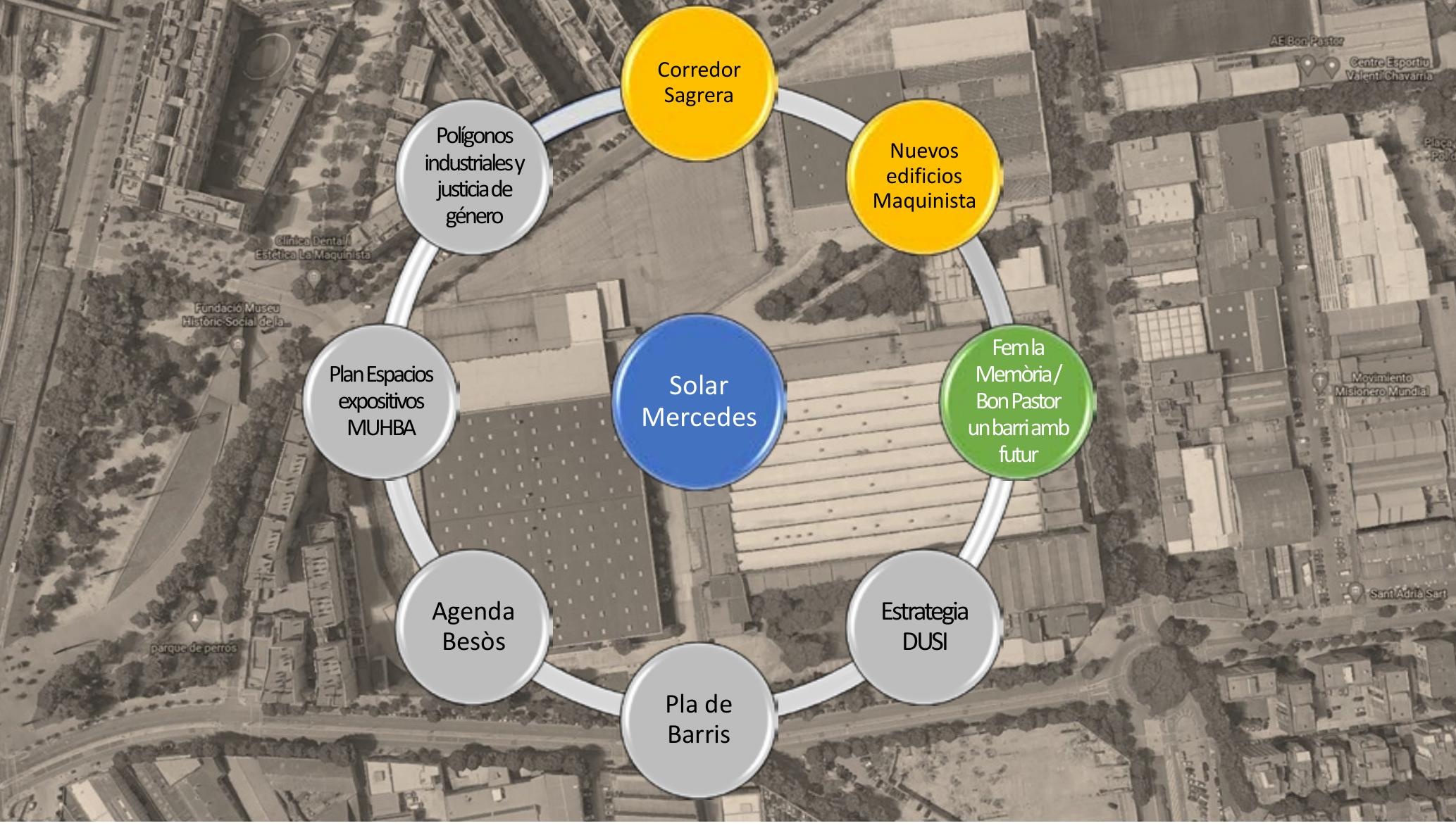

Posición central de la "operación Mercedes" en el marco del conjunto de proyectos que se están llevando a cabo en Bon Pastor

\section{Y llegó la pandemia}

La actual crisis de la pandemia del COVID-19 plantea serias reflexiones acerca, tanto del sistema de producción, cuanto a las formas de vida que todos llevamos.

Sin embargo, aún no sabemos el alcance de la crisis y sus efectos posteriores y sería precipitado avanzar conclusiones y, más aún, modelos de una futura sociedad, especialmente si tenemos en cuenta algunas de las predicciones del Imperial College de Londres que alarga la situación de crisis por 18 meses y aprendemos de los efectos de las grandes crisis médicas como la pandemia de "Gripe española" de 1918.

Lo que sí se ha hecho patente durante estos primeros días de la crisis es la actitud de la ciudadanía que ha entendido que su superación requería una actitud positiva, cooperativa y solidaria para poder superar esta primera etapa de la crisis.

Agricultores, limpiadores, transportistas, conductores de autobús y metro, reponedores, cajeros de supermercado, policías, sanitarios (personal del SEM, paramédicos, farmacéuticos, celadores, enfermeros, médicos) forman una primera línea de lucha para contener la expansión del virus y limitar su mortalidad, tras la que una ciudadanía disciplinada, desde su confinamiento, aplaude diariamente la valiente actitud de todos aquellos que permiten que podamos mantener el mínimo ritmo vital y cotidiano y propone pequeñas aportaciones para solucionar el problema (desde la fabricación de mascarillas, cocinar para los que no pueden salir de casa, a ceder los vehículos particulares a los sanitarios), al tiempo que creativamente inventa fórmulas para que los vecindarios se sientan acompañados y partícipes de una misma lucha. 


\section{En la operación "Mercedes"...}

El trabajo de "Taller de Gestión de Proyectos" iba a estar orientado a analizar la operación "Mercedes" y proponer ideas para el espacio público de esta gran macro-manzana. El desarrollo de los acontecimientos actuales imposibilita pensar en que podamos volver a las aulas presenciales y al trabajo grupal de proyectos.

Por ello hemos reorientado el trabajo de la asignatura a una propuesta que permita el trabajo individual y nos permita alcanzar la adquisición mínima de conocimientos y competencias planteados en la programación del curso.

Partiendo de la documentación que hemos estado trabajando para preparar el curso se propone trabajar una propuesta de MONUMENTO A LA CIUDADANÍA SOLIDARIA. Un monumento en positivo que nos recuerde que solidariamente unidos podemos alcanzar metas muchas veces inimaginables.

Como idea positiva nuestra propuesta está lejos de algunas ideas oportunistas que han lanzado políticos como la presidenta de la Comunidad Autónoma de Madrid. La idea de la presidenta Ayuso se fundamenta en un oxímoron, puesto que propone erigir un monumento en términos contradictorios. Monumento a las "víctimas" y monumento "de agradecimiento a los sanitarios". Para más inri la presidenta plantea el monumento como una acción concretada "público- privada", en el territorio de Madrid Nuevo Norte. La propuesta de la presidenta Ayuso es una propuesta en

\section{negativo.}

Tras hablarlo entre el equipo docente consultamos a la Asociación de Vecinos del Bon Pastor que ha dado su soporte a la idea, como un medio de dinamizar la reflexión sobre los futuros usos del antiguo espacio de la Mercedes-Benz, pero con la recomendación de que la propuesta fuera en positivo. Es decir que las propuestas para este posible monumento, se orientaran a celebrar las actitudes positivas de la ciudadanía.

\section{La propuesta espacial para el solar}

Para orientar el trabajo que precisaba tener una clara referncia de dimensionado y de volumetrías de edificación, se elaboró la siguiente propuesta, con el objetivo de que los trabajos se desarrollaran específicamente acerca del monumento, su emplazamiento y espacio circundante.

- La súper-manzana "Mercedes" tiene 345 m de longitud transversal entre fachadas, según acotación en la planta, y por tanto hace casi 3 manzanas del Eixample, el parque Joan Miró hace 2x2 manzanas del Eixample, la Universidad central hace 2x1 manzanas

- Una manzana del Eixample tiene $113 \mathrm{~m}$ entre fachadas, y $133 \mathrm{~m}$ entre ejes de calles normales, con excepciones como el paseo de Gracia que ya existía antes del Eixample y que tiene manzanas más largas.

- Una calle del ensanche hace $20 m$ de ancho con aceras de $5+5 m$ y calzada de $10 m, 50 \%$ para 


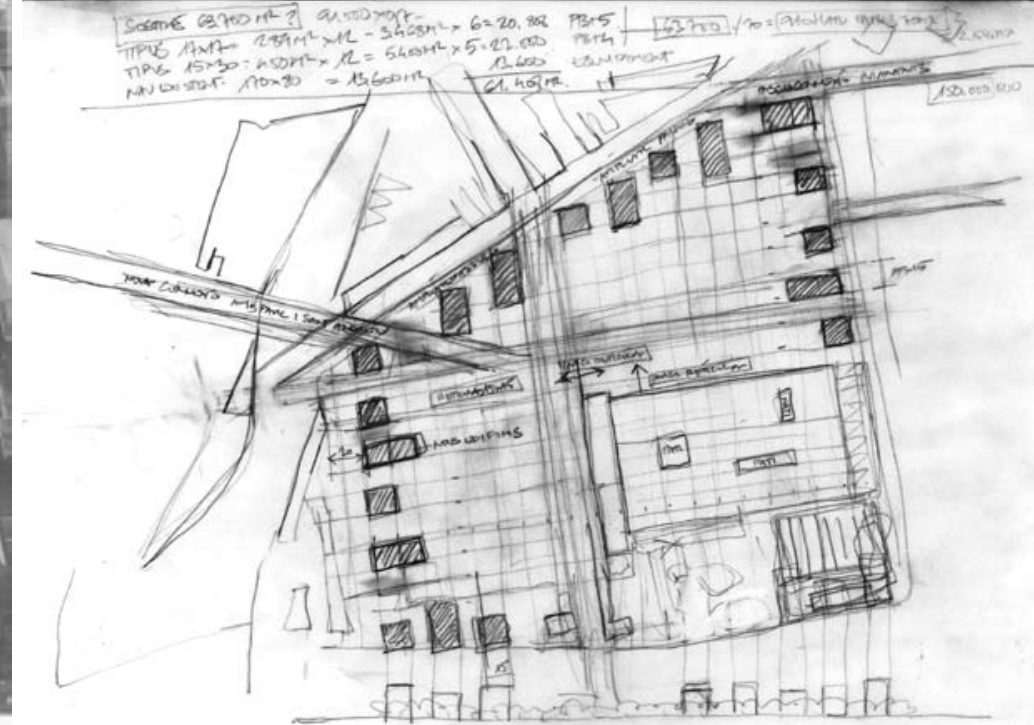

Estudio inicial de la organización de la planta y de las volumetría delos edificios (J. Henrich, 2020)

peatones y $50 \%$ para vehículos, la rambla de Cataluña hace $30 \mathrm{~m}$, como las calles perimetrales de la súper-mançana "Mercedes"; Gran Via, Diagonal, Marina, P San Juan hacen 50m, Paseo de Gracia hace $60 \mathrm{~m}$

Jordi Henrich organizó una trama base dibujada en la planta es de $15 \times 15$ m que es el doble de la estructura tipo para aparcamiento subterráneo que es de 7,7x 7,5m entre ejes de pilares. Los edificios están dimensionados según esta trama y hacen $15 \times 15 \mathrm{~m}$ los cuadrados y 15x50 m los rectangulares, los cuadrados tienen 10 plantas de altura y hacen $31 \mathrm{~m}$ de altura, PB $4 \mathrm{~m}$ y otras plantas $3 \mathrm{~m}$, y los edificios rectangulares, tienen 5 plantas de altura y hacen $16 \mathrm{~m}$ de altura.

Este tipo de edificació alrededor del perímeto de la manzana, permitía abrir el espacio interior como espacio público, conectar las diversas partes del territorio de manera permeable, porosa, y evitar los problemas de "calle ciega" presente en los edificios de residencial La Maquinista. La diferencia de alturas y profundidades del edificado permitían crear ritmos y modulaciones. La propuesta plantea, también, la posibilidad de utilizar las plantas bajas e incluso la primera planta, tanto para comercio como para actividades nuevas industrias.

Respecto al monumento, se plantea que puede ser una pieza concentrada, única, o puede ser varias piezas concentradas y repartidas en un ámbito reducido, o bien incluso en un ámbito más amplio. Ej.: La escultura Ondas es muy grande y ligera y diáfana, y es una pieza repartida en un ámbito amplio, y con cargas puntuales. Está apoyada sobre la losa de la ronda litoral en parte. La propuesta del monumento deberá contemplar el uso de agua y luz.

Se plantea que la propuesta debe contener algún elemento vertical que posibilite su visión desde el espacio circundante, teniendo en cuenta que:

- Una estructura escultórica de $15 \mathrm{~m}$ de altura y una planta colocada sobre la trama $15 \times 15 \mathrm{~m}$ es un cubo, evidentemente;

- Como que las estructuras pesan sería conveniente que se colocara según la trama de los pilares de la estructura de la parte inferior y sobre los pilares para transmitir las cargas directamente a los pilares: esto puede ser un condicionante interesante 


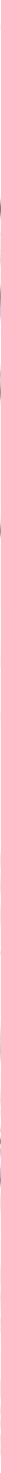

Planta y sección longitudinal final. Se facilitó una versión dwg a los estudiantes, para el desarrollo del trabajo (J.Henrich, 2020)

- Las columnas altas de alumbrado cilíndricas con proyectores habituales en BCN, las Prim y equivalentes, hacen $15 \mathrm{~m}$ de altura

- La escultura monumento a los Castellers de la plaza San Miguel, hace 26,5m de altura, casi 30 m, que sería el doble de una columna Prim

- En ningún caso se admitirán soluciones visuales que estilísticamente podamos enmarcar en las categorías de "realista" o "figurativa"

- En ningún caso se admitirán soluciones tipo "mural" puesto que supondría la introducción de una estructura que "cegaría" puntos del espacio público, ni tampoco soluciones basadas en el mal denominado "arte urbano"

Complementariamente, se planteó que el monumento contemplara la inclusión de mecanismos (QR o Beacon) que permitieran RA (realidad aumentada) por medio de teléfono móvil. 


\section{Para concluir}

El trabajo se desarrolló de forma individual y con seguimiento semanal basado en sesiones de discusión on-line y en el retorno individualizado de un informe de seguimiento.

Los artículos que siguen muestran tres de los trabajos presentados que, a nuestro entender, reúnen condiciones suficientes para poder servir de "laboratorio de ideas" a los vecinos del Bon Pastor, tanto por lo que hace a la formulación espacial y edificatoria, como en la idea de organizr un espacio público a partir de un monumento. Monumento a la ciudadanía solidaria, en un barrio solidario y combativo como es el de Bon Pastor. Monumento en positivo y con capacidad de persistir en el tiempo como referencia, no solo del recuerdo de la pandemia, sino, lo más importante, de la capacidad de la ciudadanía para autorganizarse y expresar su solidaridad. Como han repetido incesantemente los trabajadores de la salud pública, "esto no va de héroes" sino de esfuerzo colectivo. El monumento puede "centrar" este centro que es el actual solar, funcionando como signo de exclamación.

No conocemos el devenir de la operación Mercedes, pero si tenemos la convicción de que la remodelación de este territorio no puede levantar fronteras, que pueda producir una segregación invisible entre vecindarios. Debe ser un espacio poroso, una membrana, " en una ciudad cerrada predominará la frontera; una ciudad abierta tendrá más lindes. Estos lindes funcionan como membranas celulares, con tensión dinámica entre porosidad y resistencia" (Sennett, Richard 2018, 360).

\section{Referencias}

AGOSTINI, F. 2015. 'ENMASA. EMPRESA NACIONAL DE MOTORES DE AVIACIÓN SA. Robert Terradas i Via'. Master Thesis, Barcelona: Politècnica de Catalunya. https://upcommons.upc.edu/handle/2117/99541.

ALCAIDE, Rafael. 2005. 'El Ferrocarril Como Elemento Estructurador de La Morfología Urbana: Barcelona 1848-1900'. Scripta Nova. Revista Electrónica de Geografía y Ciencias Sociales, 2005.

ANGOSTO, SALAVADOR. 2019. 'Mapping the History of a Territory: Bon Pastor (Barcelona) - Social Remembrance and Heritage Project'. Acta Universitatis Lodziensis. Folia Philsophica-Ethica-Aesthetica-Practica, no. 33: 37-55. https://doi.org/10.18778/0208-6107.33.03.

AA.VV del BON PASTOR / CR POLIS. Exposición "Bon Pastor un territorii canviant", 2020

AYUNTAMIENTO DE BACELONA. 1927. Ordenanzas Municipales En La Parte Que Se Refiere a Obras Particulares. Tal Como Han Quedado Redactadas En Virtud Del Acuerdo Adoptado Por El Ayuntamiento Pleno En Sesión de 21 de Noviembre de 1927. Gaceta Municipal de Barcelona. Vol. 48. http://hdl.handle.net/11703/106691.

AJUNTAMENT DE BARCELONA. 2004. 'Criteris Orientadors per a La Transformació d'àrees Industrialas a Bacelona'. https://ajuntament.barcelona.cat/informaciourbanistica/cerca/es/fitxa/B1003/-----ap/.

AJUNTAMENT DE BARCELONA.. 2007. 'Criteris de Planejament per a La Transformació Urbanística de La Parcel.La Situada al Carrer de Sant Adrià, Núms. 55-79 (Fàbrica Mercedes Benz)'. https://ajuntament.barcelona.cat/informaciourbanistica/cerca/es/fitxa/B1003/--/--/ap/.

BARCELONA REGIONAL. 1999. Barcelona Nous Projectes / Barcelona New Projects. Barcelona: Ajuntament de Barcelona.

BERRI, André. 2018. 'Às margens de Barcelona. O plan de la Ribera (1965) como ponto de convergência dos processos de regeneraçâo urbana na frente marítima.' Master, Barcelona. http://hdl.handle.net/2445/120909. 
BONET CSTELLANA, A. 1965. Barcelona, Una ciudad que no puede seguir viviendo de espaldas al mar,. Barcelona: Costa Padrò.

BUSQUETS, Joan. 1998. 'Estudi de Detall. Ordenació de l’edificació Del Sector Residencial Maquinista'.

BUSQUETS, Joan. 1999. 'Residencial La Maquinista'. In Esteban, J \& Barnada, J. 1999 Urbanisme a Barcelona, 62-63. Barcelona: Ajuntament de Barcelona.

CANTALLOPS, Lluís; MONTERO, J.M; SOLÀ-MORALES, Manuel de S; TORRES, Manuel de; ROS HOMBRAVELLA, J; ESTEBAN, J; RIBAS PIERA, Manuel; FONT, Antonio. 1972. 'El Area Metropolitana de Barcelona.' Cuadernos de Arquitectura y Urbanismo [En Línia], 1972.

CHECA ARTASU, M. 1999. 'Fábrica y Arquitectura En Barcelona: Entre Lo Mimético y Lo Mastodóntico (1950-1965)'. In DOCOMOMO Ibérico. Arquitectura e Industrias Modernas 1900-1965. Actas Segundo Seminario, 107-12. Sevilla: DOCOMOMO Ibérico.

CHECA ARTASU, M.; GIMENO, Pilar. 1998. '«Anatomia d'un Paisatge Industrial. Districte IX-Sant Andreu (19061934)»’. Finestrelles, [En Línia], 1998. https://www.raco.cat/index.php/Finestrelles/article/view/214531.

CHECA ARTASU, M.; BASIANA, X. 2000. Barcelona, Ciutat de Fàbriques. Barcelona: Nau Ivanov.

CHECA ARTASU, M; TRAVÉ, C . 2007. Bon Pastor Història d’un Barri. Barcelona: Ajuntament de Barcelona; Districte de Sant Andreu.

DOMINGO, M -BONET, M.R. 1998. Barcelona i Els Moviments Socials Urbans. Barcelona: Fundació Jaume Bofill.

DOMINGO, M,- SAGARRA, Ferran. 1999. Barcelona. Les Cases Barates. Barcelona: Ajuntament de Barcelona.

ECHENIQUE, M . 1965. 'Plan Especial de Ordenación de Montjuïc, Arquitectos: O. Bohigas, A. Bonet y J.M. Martorell'. Cuadernos de Arquitectura [En Línia], 1965. http://raco.cat/index.php/CuadernosArquitectura/article/view/110014 [Consulta: 13-09-16].

FAVB (Federació de Veins de Barcelona). 1997. La Barcelona de Maragall. Barcelona: CAVE.

GRANDA, Manu. 2019. 'El Beneficio de Mercedes Se Dispara Un 88\% En España Por Laventa de La Planta de Barcelona'. Cinco Días, 11 August 2019. https://cincodias.elpais.com/cincodias/2019/08/09/ companias/1565377810_074625.html.

REDACCIÓN. 2007. 'La Vieja Fábrica de Mercedes Albergará 1.000 Pisos Protegidos'. El País, 21 December 2007, Barcelona edition.

RÍOS DÍAZ, Marien. 2017. '¿Hacer Ciudad? Barcelona, La Construcción Del Paisaje, 1929-1973’. Doctoral, Barcelona: Universitat de Barcelona. http://hdl.handle.net/10803/481954.

SANTAMARÍA CONCHA, J. A. 2018. 'La periferia en transformación... Procesos de cualificación del espacio público. El caso del barrio del Bon Pastor'. M.A., Barcelona: Universitat de Barcelona. http://hdl.handle.net/2445/122523.

SENNETT, Richard. 2018. Building and Dwelling. Ethics for the City. New York: Farrar, Strauss and Giroux.

TAJAdURA, J.A.,BERENGUÉ, M, COSTA, A, and LAMBIES, E. 1996. 'Sant Andreu/La Sagrera. Modificacio Del PGM al Sector de Sant Andreu-La Sagrera'. In Sector d'Urbanisme. Barcelona La Segona Renovació. Barcelona: Ajuntament de Barcelona

TATJER, Mè. 2006. 'La Industria En Barcelona (1832-1992). Factores de Localización y Transformación En Las Áreas Fabriles: Del Centro Histórico a La Región Metropolitana.' Scripta Nova. Revista Electrónica de Geografía y Ciencias Sociales X (218(46)). http://www.ub.es/geocrit/sn/sn-218-46.htm.

TORRES CAPELL, Manuel de. 1999. La Formació de La Urbanística Metropolitana de Barcelona. Barcelona: Mancomunitat de Municipis de l’Àrea Metropolitana de Barcelona.

\section{RECONOCIMIENTOS}

Este trabajo forma parte del proyecto de investigación HAR2017-88672-R financiado por el Ministerio de Ciencia e Innovación 
